\title{
Commercial secret as an instrument of company competitive strategy effectiveness increase
}

\author{
Dinara Peskova ${ }^{1, *}$, Yuliya Vasileva $^{1}$, and Mikhail Nazarov ${ }^{2}$ \\ ${ }^{1}$ Department of Economics, Ufa State Petroleum Technological University, Ufa, Russian Federation \\ ${ }^{2}$ Department of Taxes and Taxation, Samara State University of Economics, Samara, Russian Federation
}

\begin{abstract}
Modern companies are very much diversified in scale, sectoral affiliation, marketing behavior. There are many theoretical and applied studies in effective competitiveness strategies (see Porter, M. (2002, 1998), Kramer, M. (1998), Fatkhutdinov, R. A. (2000), Feigelson, V. M. (1996) and others).They present famous approaches and probably there is no need to repeat them in this article. We would like to feature a different concept (suggested by Yudanov A. and followers) with terminology adopted from natural sciences and show the way the commercial secret can increase effectiveness of competitiveness strategy. We also perform valid methods of commercial secret protection.
\end{abstract}

In conditions of functioning in highly competitive market companies are looking for innovative instruments to raise the effectiveness of their business.

Information is one of the most significant factors of production in modern economies. Modern entrepreneurship depends as much on the possession of information about potential customers, trade venues, and technical data as it does on personnel, machinery, and other capital goods. The reliance of industry on rapidly developing technologies amplifies the value of information. However, information is also different from other types of economic resources. It can be divided into an infinite amount of parts and, hence, is very complex. Importantly, it is often impossible to guarantee exclusive possession of this resource. The concept of "trade secret" was developed to limit access to such commercially valuable information.

A "commercial secret" is a piece of confidentially kept information that gives an entrepreneur some economic advantage over competitors. This could range from information about specific production techniques or production formulas to marketing strategies or customer data.

There are plenty of ways to classify the companies. According to implemented marketing strategy there can be outlined four types of companies: Explerents, Patients, Violents and Commutants [11]. Using the existent classification we will suggest the most effective pattern of economic behavior for them based on differences of using mechanisms and amounts of commercial secrets.

Explerents are the pioneers of business. The strategies they realize are oriented into risky innovations based on applying the newest highly-efficient technologies leading to maximal profit, venture investments. According to expert's estimations risks of this type of strategy are extremely high. The most positive approximations give three out of ten venture projects reach the break-even point, six loose and only one can become highly profitable.

Patients are pointed into niche specialism and production of small batch of elite goods and overcharge purchasers. Usually their goods are of very elastic demand what commits them to the tough forms of competitive struggle.

Violents as a counter to patients prefer overt price competition. They orientate to the mass-market customer and strife towards cost reduction.

Commutants are small, non-specialized companies. They are very flexible and use any possibilities for business but usually don't possess extended manufacturing nor Research and Advanced Development capacities. Commutants cover the remaining after all others part of market. These companies tend to seize the competitors' commercial secrets rather than create themselves. This is why we do not emphasize their role in our research.

The three basic marketing strategies use commercial secret as an instrument to gain competitive advantage though the content and amount of information classified as a commercial secret differ (Fig. 1).

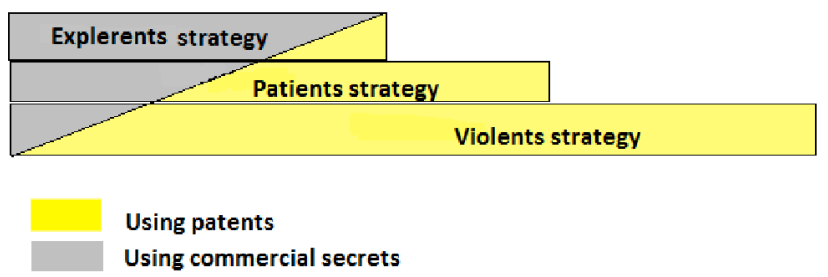

Fig. 1. Basic marketing strategies.

\footnotetext{
*Corresponding author: peskovad@yandex.ru
} 
Explerent competitive strategy. The companies following this strategy direct most efforts into research and advanced development path-breaker activity. Their best advantage and the condition of high -profit earning is the anticipating implementation of principal innovations. Taking high-level risk explerent companies build up new markets and get the most benefit out of monopoly position. These companies will combine patents and commercial secret instruments. The reasons to use commercial secret versus patent are: 1) the process of filing of an application for patent is timetaking and thus the pioneer position can be disrupted, the competitor can appear and start production first; 2) patenting inherits additional expenditure ; 3) patent provides long-lasting protection (ex. 20 years) which is not a goal for explerents, the supernormal profit is possible to get only in short-run period. These factors explain the propensity of explerents to use commercial secret but some companies will patent technologies aiming to commercialize them to other market participants (for example to Patients). Patent protection facilitates the process of scientific research results circulation. Combing of both systems of information protection allows the companies use commercial secret during the initial stage and the period of patent execution and later in case of favourable decision - use patent. Portfolio models are also possible - some innovations are under the commercial secret protection, others hold a patent. Explerents' commercial secrets consist of engineering solutions, rarely organizational decisions and more rarely client databases.

Patient strategy in Russian economic reality is inclined to production and research programs which are realized by the companies inventing science-intensive technologies.

Patient market strategy is typical for monotechnic companies. It provides production of special, nonordinal goods for certain narrow circle of customers. Patient-companies draw market strength from their position of manufacturers of irreplaceable goods for some niche of clients. These firms tend to control a small amount of market, addressing their expensive and high-quality articles to those consumers who are not satisfied with standardized goods. Patients shirk direct competition with leading corporation. They will rather consider and gratify the very special consumer requests. Patients vary the markets.

Usage of commercial secrets by companies of patient strategy is determined by mostly the same reasons as for explerents but additionally due to their narrow specialization commercial secret can provide them more advantages. Business of patients companies is already protected by entry barriers such as equipment cost, workers' skills, required technological base. This is why coping of their goods is complicated and unpromising: all possible competitors of patient markets are well-known and appearance of very new participant is seldom. Commercial secrets of patient strategy companies include technological, organizational and commercial information.

Violent competitive strategy is mostly directed to maximal price reduction due to cutback of expenditures.
The main point is to orientate into large turnout of standardized goods. This type of production is less-cost in compare with manufacturing small lots of varied goods. Violent-companies aim to dominate in wide market attracting customers with low price and satisfactory quality. Violents acting in a massive demand market are less interested in protection of their technologies with commercial secret because: 1) they are not screened with entry barriers and need to be protected with patent; 2) they are in need of advertisement that leads to necessity to open part of technological advantages to pull custom, 3) they are more susceptible to reverse engineering methods. Though unpatentable information should be classified.

This classification leads to the following conclusions:

1) while selecting the competitiveness strategy the company initially should pay enough attention to commercial secret protection.

2) if companies (especially violents) report of intensive commercial secret usage, it's a sign for regularity authorities about unfair business practice.

The technology of science-intensive products invention and its entry into the goods market includes several stages (Fig. 2):

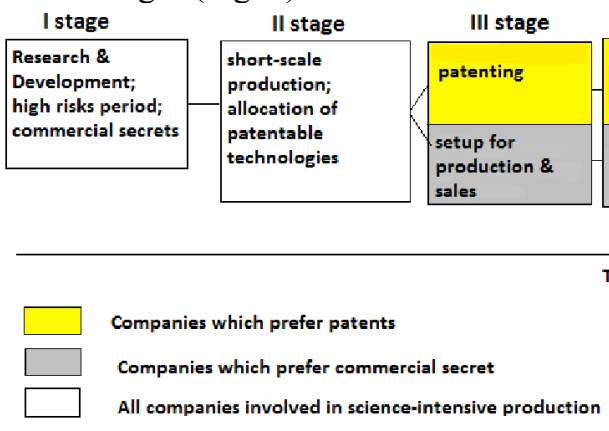

Fig.2. General stages of science-intensive production.

The first stage consists of research and development activities. This is the period of the highest risk of valuable information leakage and the only effective instrument of protection is commercial secret

The second stage is the start of short-scale test production, demand research and product's determining of patentability. Depending on this stage's results the direction of further performance shall be selected: using patent or commercial secret.

On the third stage companies preferred miscellaneous methods of information protection act differently. Entrepreneurs using commercial secret can start to setup for large-scale production and sales. Patent-focused companies should spend additional time to get through the application for patent procedures and thus can startthe large quantity manufacture only on the next stage.

The presented stages of science-intensive production process, general and universal for companies any competitiveness strategy, show that usage of commercial secret protection significantly increases effectiveness of entrepreneurial activity aiming to innovations. 
In compare with patenting the advantage of commercial secret is its ability to protect 1) ideas; 2) non-patentable objects which cannot be treated as discoveries, useful models, utility inventions; 3) delinked information; 4) negative advance (which is information about negative results of explorations); 5) damaging information; 6) information with very short and very long-run usage period.

The downside of commercial secret is low disclosure hardness. It can be subject to simple analysis, expert "data pump" or random seepage.

Provisionally the process of commoditization divided the information kept as commercial secret into two types:

- inalienable commercial secret provides safety and competitive integrity of internal company's activity; seizable commercial secret which gained the status of commodity.

In practice the inalienable type of commercial secret is mostly spread while seizable commercial secret is better protected by patents to facilitate the commercialization process.

The complex work on identification of threats to safety should preface the data protection system setup. The sequence of actions will include: detection of threats (probability levelevaluation, systematization); estimation of potential loses; preliminary selection of commercial secret protection; estimation of economic effect and costs. The following classification of threats to the commercial secret owner can be suggested (Table $1)$ :

Table 1. Commercial secret threats classification.

\begin{tabular}{|c|c|}
\hline Criteria & Types \\
\hline Threat source & $\begin{array}{l}\text { External (business espionage, } \\
\text { competitors illegal acts, stealing of } \\
\text { tangible and intangible assets and } \\
\text { valuables); } \\
\text { Internal (disclosure of confidential } \\
\text { information by the employees, low } \\
\text { work motivation, non-effective } \\
\text { security service) }\end{array}$ \\
\hline $\begin{array}{l}\text { Severity level } \\
\text { of } \\
\text { consequences }\end{array}$ & $\begin{array}{l}\text { Threats with heavy severity level } \\
\text { result in all economic indicators } \\
\text { breakdown and stop of business } \\
\text { activity; threats with mild severity } \\
\text { level require high expenses on } \\
\text { recovery but not much time; threats } \\
\text { with low severity level have potential } \\
\text { disruptive affect. }\end{array}$ \\
\hline $\begin{array}{l}\text { Probability of } \\
\text { threat } \\
\text { execution }\end{array}$ & Hardly probable threats; real risk \\
\hline $\begin{array}{l}\text { Stage of } \\
\text { firm's } \\
\text { functioning }\end{array}$ & $\begin{array}{l}\text { Onstage of initialization; on stage of } \\
\text { consistent production. Threats on } \\
\text { initializing stage are more dangerous } \\
\text { than others. }\end{array}$ \\
\hline $\begin{array}{l}\text { Object of } \\
\text { infringement }\end{array}$ & $\begin{array}{l}\text { Information; finances; tangible } \\
\text { assets; good will and others }\end{array}$ \\
\hline $\begin{array}{l}\text { Subject of } \\
\text { infringement }\end{array}$ & \begin{tabular}{lcr} 
Organized & crime; & \multicolumn{2}{c}{ unscrupulous } \\
competitors; & employees, & state
\end{tabular} \\
\hline
\end{tabular}

\begin{tabular}{|l|l|}
\hline & authorities. \\
\hline $\begin{array}{l}\text { Disbenefit } \\
\text { type }\end{array}$ & Direct; lost profit. \\
\hline
\end{tabular}

The existent practical methods of commercial secret protection can be grouped upon functional criteria (Fig.3):

1. Documental methods include rules of circulation of internal papers containing the confidential information. The status "Commercial secret" is considered to be set up after the confidentiality safeguard measures are taken:

a. make a list of confidential information to be kept as commercial secret;

b. take steps to regulate the inside relations upon realization of commercial confidential information by employees according to Labor contracts, by business partners on the ground of civil law treaty;

c. mark the physical media on which confidential data are stored with "Commercial secret' label, pointing the owner of the information;

d. use means and methods of technical protection of information.

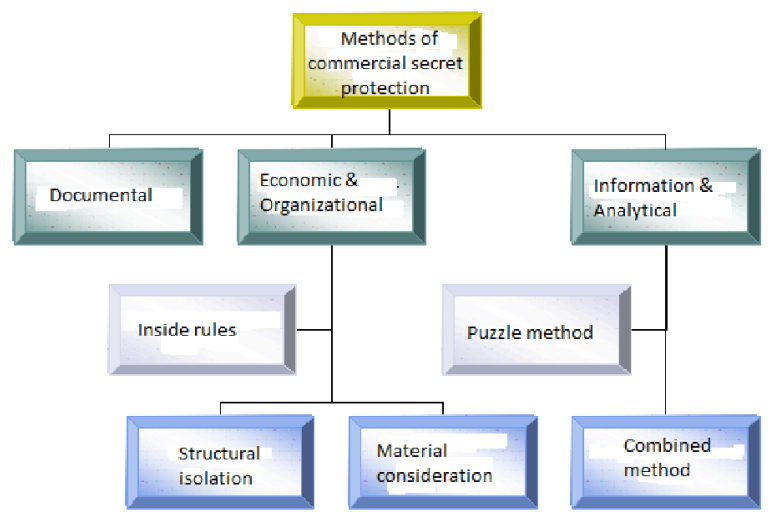

Fig.3. Commercial secret protection methods.

This group of methods consists of formal and legal regulations. Their obvious advantage is apprehensibility and clarity of commercial secret protection policy though in practice can protect mostly from unintended seepage. Execution of named actions will provide an evidentiary foundation in litigation in case of commercial secret loss. However the judicial settlement is usually the measure of last resort which indicates of irrecoverably loss of confidential information. Moreover often austerity measures may result in negative spinoffs: they induce and routinize the infringements.

2. Economic and organizational methods. In the context of institutional economic approach an employer has three basic measures to protect commercial secret for leakage. 1) establish the corporative rules of commercial secret handling; 2) the system of compensational payments to the employees for creation and keeping commercial secrets; 3)the structural isolation of particular departments. Let's take a closer look to each of these methods.

a. Inside corporative rules. Every employer inside the company is authorized to set and request exact obedience of certain rules. Execution of employment 
agreement implies that the employee agrees to comply with the rules. Institution of exact instructions on commercial secret handling is the most obvious step though constrained with weak points the main of which is ineffective sanctions for rule breakage. The problem is that sanctions don't prevent losses. The inside rules can be of different types: 1) norms which limit social intercommunications of employees. When the confidential information is mostly in viva voce and is not formally arranged, even in a simple personal conversation the secret loss can take place. The standard example of this type of rules prohibits intercorporate communications with competitors existent or potential. And also this includes the rules regulating the right of access to company's documentation, system of passwords and physical entry to certain premises. Elaboration, implementation and enforcement of corporative rules of commercial secret handling build an additional expense item increasing progressively as the rules intensify. Thus The Wall Street Journal provides an example of IBM which has established intracorporate rules of work flow which stipulates a special envelope for each document according to its confidentiality level. There were four different types of envelopes designed in order of secrecy increase: "For internal use only"; "Confidentially"; "Strictly confidentially"; "Particular confidentially". Annual demand for envelopes estimates of 4 million pcs. that makes 400, 000 USD were spent for the envelopes [10]. Here also have to be added the increased transactional costs to obey the safety rules.

b. Inside corporative rules should be backed with financial compensation for creation of marketable information, so called "hush money" It's an analogue to informational rent distribution. Thus personal involving generates what makes this method effective. The difficult side is to calculate the exact amount of the compensation. The upper boundary is the maximal slate of informational rent the employer is able to share, without entrepreneurial motivation decrease. The lower bound is determined by minimal agreeable for the employee amount. Therefore the employer sets the maximum while the employee - the minimum of the compensation level of commercial secret protection. In any case the size of compensation shall relate to the damage the loss of secret can cause. Moral encouragement of workers is worthy of special mention. Moral incentives unit people in a team, raise corporative spirit, give psychological drive to demonstrate loyalty.

c. Structural isolation is the third method of information protection, the main idea of which is access restriction to certain premises for visitors and noninvolved employees. The advantage of this method is in narrowing the asset to be protected from the whole company to a certain premise or department. This raises effectiveness of defense measures. Structural isolation might be supplemented by geographical reference.

3.Information and analytical group of methods includes techniques of secure commercial secret usage in production process.

a. Puzzle method suggests to separate commercial secret into parts with different conditions of access and use [5]. All parts together make a mosaic picture of commercial secret content while separate pieces might look like having no commercial value. Some parts of the puzzle can be formally completed as commercial secret, others might not. Only the chief executers understand the puzzle in whole, so this method impedes holistic comprehension of commercial secret content by third party as well as by company's employees. The disadvantage is complexity of puzzle elaboration and unintended loss occurrence (for example providing too much information in scientific conferences, mass media, personal communications, neglectful treating of sensitive documents alleged to be insignificant.).

b. Combing patent and commercial secret. This method suggests that the patentable technologies record a patent while another part of commercially valued information get classified. The described method combines advantages of two system of data protection and compensates for a shortcomings. As a disadvantage of patent experts list the following: limited time of protection, technical narrowness (sometimes patenting of exact technology or invention can give a nudge for competitors of similar but modified model) expensiveness. Free circulation, commercialization, legal legitimacy are undoubtable advantages of patent which are able to improve efficiency to commercial secret if combined.

Trade secrecy is a special economic institution. Commercial secret can be used as an effective instrument for competitiveness raise as it was shown in our paper. Different types of companies use it according to market strategy employed. Methodology of usage the commercial secret is a powerful base for confidential information protection.

\section{References}

1. About commercial secret: Federal Law of Russian Federation dated 2004 no. 98-FZ. http://www.referent.ru/1/109717/nav

2. R.A. Fatkhutdinov, Competitiveness: economics, strategy, management (Infra-M, Moscow, 2000)

3. V.M. Feigelson, Basic principles of intellectual property protection and use (VNIIPI, Moscow, 1996)

4. V.V. Mokryshev, V.M. Aldoshin, Management of exclusive rights (intellectual property, intangible assets) in competitive struggle (RosPatent publishing, Moscow, 2002)

5. N. Nyrovova, Industrial property, 11, 45-54 (2008)

6. D.R. Peskova, Creative economy, 5, 103-109 (2010)

7. D.R. Peskova, ESSJ, 7, 331-338 (2011)

8. M.E. Porter, Competitive Strategy: Techniques for Analyzing Industries and Competitors (Free Press, 1998)

9. M.E. Porter, M.R. Kramer, The Competitive Advantage of Corporate Philanthropy (Harvard Business Review, 2002)

10. The Wall Street Journal (1995)

11. A.Yu. Yudanov, Competition: theory and practice (Gnom Press, Moscow, 2001) 